\title{
Minireview
}

\section{Mdm2: The Ups and Downs}

\author{
Tamar Juven-Gershon and Moshe Oren \\ Department of Molecular Cell Biology, Weizmann Institute of \\ Science, Rehovot, Israel
}

\section{Introduction}

Mdm2 was first described 12 years ago. Interest in this oncogene has risen since its identification as a protein that binds and efficiently inactivates the p53 tumor suppressor protein. This interest was further boosted by the discovery that the $m d m 2$ gene is actually a target for direct transcriptional activation by $\mathrm{p} 53$, thus defining an autoregulatory feedback loop for the intracellular modulation of $\mathrm{p} 53$ function. Subsequent work has revealed that the Mdm2 protein is engaged in a complex network of regulatory interactions. In addition to p53, these involve several other interesting protein partners, including critical cell cycle regulators such as pRb, E2F1/DPl, and p19ARF. Through these interactions, $\mathrm{Mdm} 2$ now appears to exert a host of effects on cell cycle, apoptosis, and neoplastic transformation.

Several recent excellent reviews offer a detailed discussion of the $\mathrm{Mdm} 2$ protein and its various functions (1-3). In the present minireview, we will attempt to highlight some exciting new insights into Mdm2, its biochemistry, and its biology.

\section{Mdm2: The Cancer Connection}

The $m d m 2$ gene was originally cloned from a spontaneously transformed mouse 3T3 cell line, where it had been heavily amplified and was present in multiple copies on double minute chromosomes [hence its name: mouse double minute; (4)]. Overexpression of the Mdm2 pro-

Address correspondence and reprint requests to: Dr. Moshe Oren, Department of Molecular Cell Biology, Weizmann Institute of Science, 76100 Rehovot, Israel. Phone: 9728 934 2358; Fax: 97289465223 tein was found to confer tumorigenic properties upon rodent fibroblasts, as measured by tumor formation in nude mice (5). Overexpressed Mdm2 was also shown to immortalize primary rat embryo fibroblasts, as well as transform such cells in cooperation with oncogenic ras (6). Moreover, Mdm2 can also overcome suppression of transformed cell growth by wild-type (wt) p53 (6). More recently, targeted expression of Mdm2 to mammary glands was found to result in mammary tumors (7).

Amplification of the $m d m 2$ gene is observed in a variety of human tumors; an $m d m 2$ gene amplification database, available on the World Wide Web, has recently been compiled and described by Momand et al. (8). Amplification of the $m d m 2$ gene is present in a significant percentage of soft tissue sarcomas (9-11) and osteosarcomas $(9,12)$, as well as a smaller subset of esophageal carcinomas (13), gliomas, anaplastic astrocytomas $(14,15)$, and neuroblastomas (16). Interestingly, overexpression of $\mathrm{Mdm} 2$ in cancer cells can also be achieved through enhanced translation of the mRNA, without gene amplification $(17,18)$. On average, it is estimated that $5-10 \%$ of all human tumors possess deregulated Mdm2 overexpression, due to either gene amplification or transcriptional and post-transcriptional mechanisms.

Several studies have addressed the correlation of $m d m 2$ deregulation with patient prognosis. $m d m 2$ gene amplification was detected more frequently in metastatic or recurrent osteosarcomas than in corresponding primary tumors (12). Studies looking in parallel at Mdm2 overexpression and p53 mutation concluded that these are usually mutually exclusive events, supporting the notion that the primary impact of $m d m 2$ am- 
DNA-PK sites *

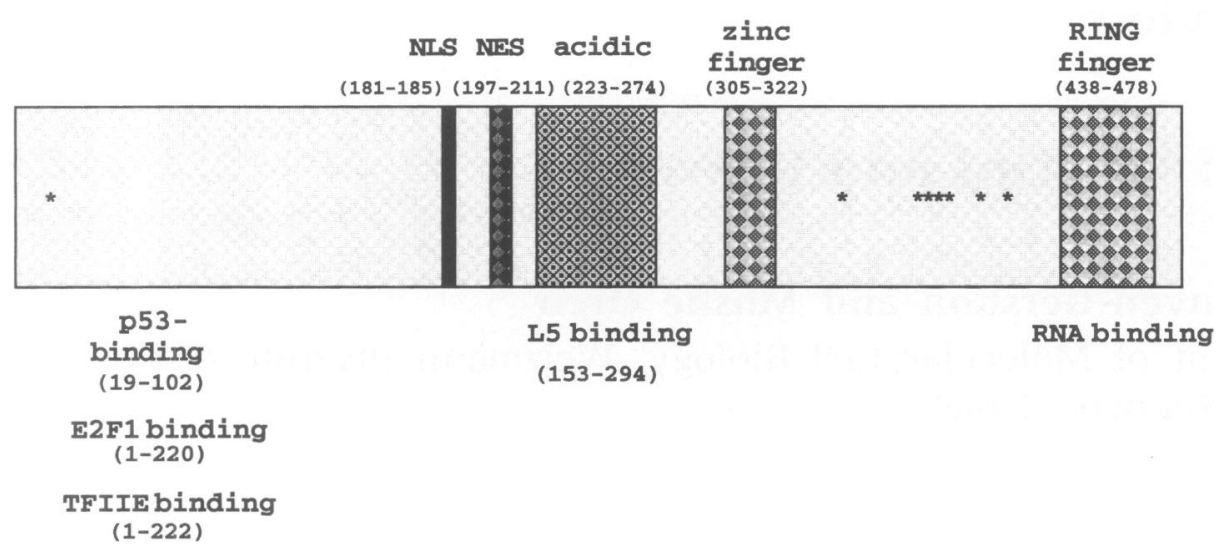

Fig. 1. Schematic map of Mdm2, illustrating functional motifs and protein-interacting domains, as well as potential sites for phosphorylation by DNA-dependent protein kinase (DNA-PK). The N-terminal site (serl7 of human Mdm2) has been shown to be phosphorylated in vitro by DNA-PK. All other DNA-PK sites are based

plification in cancer cells is the inactivation of the resident wt p53 (see ref. 8). Nevertheless, detection of elevated levels of both Mdm2 and p53 proteins, the latter being taken to imply mutational inactivation of $\mathrm{p} 53$, was shown to predict particularly poor prognosis and short survival of soft tissue sarcoma patients $(11,19)$. This suggests that, in addition to its well-established ability to inactivate $\mathrm{p} 53, \mathrm{Mdm} 2$ probably possesses $\mathrm{p} 53$ independent functions that can further contribute to its oncogenic capacity.

\section{The Mdm2 Protein}

The $m d m 2$ gene can give rise to a series of polypeptides, through the use of multiple initiation codons and alternative splicing $(20-22)$. Unless otherwise stated, when using the term Mdm2 in this review, we refer to the largest, full-length polypeptide.

The $\mathrm{N}$-terminal portion of $\mathrm{Mdm} 2$ contains the p53-binding domain (Fig. 1), and can also engage in other protein-protein interactions. Several additional structural motifs, dispensable for p53 binding, exhibit extensive evolutionary conservation and are thus likely to be functionally important $(1,23)$.

Mdm2 contains a central acidic region, capable of interacting with the ribosomal L5 protein (24). Both Mdm2-L5 and Mdm2-L5-p53 com- only on sequence predictions. The $\mathrm{N}$ terminus harbors binding sites for $\mathrm{p} 53$, as well as other proteins (see text). The central region is highly acidic and is capable of binding the ribosomal L5 protein. The Cterminal RING finger has been shown to bind RNA. *, DNA-PK sites; NLS, nuclear localization signal; NES, nuclear export signal.

plexes can bind specifically to 5SRNA (25). Additional structural hallmarks are a zinc finger motif, as well as a RING finger domain (26). RING finger domains may mediate both proteinprotein and protein-nucleic acid interactions; in fact, the Mdm2 RING finger was shown to be capable of sequence-selective RNA binding (24). Along with the above L5 interactions, this raises the interesting possibility that Mdm2 may possess as yet unidentified translational regulatory functions. In addition, the Mdm2 protein also contains a basic nuclear localization signal (5) as well as a closely juxtaposed nuclear export signal (27). These latter elements may allow the Mdm2 protein to shuttle between the nucleus and the cytoplasm, in a manner that may be important for at least some of the biochemical activities of this protein (27).

An interesting mechanism for the intracellular regulation of $\mathrm{Mdm} 2$ activity is suggested by the finding that this protein undergoes caspasemediated proteolytic cleavage during apoptosis $(28,29)$. The resultant major cleavage product misses the C-terminal RING finger, resulting in loss of RNA binding, but retains the $\mathrm{N}$-terminal p53-binding domain and is therefore still capable of inhibiting p53-mediated transactivation. The other, smaller product of the cleavage retains RNA binding ability (28). The biological role of this apoptotic cleavage remains to be unraveled. 


\section{The $m d m 2-p 53$ Autoregulatory Loop}

The Mdm2 protein forms a tight specific complex with p53 $(30,31)$, and this interaction results in inhibition of $\mathrm{p} 53$-mediated transcriptional activity $(30-32)$. At the same time, expression of the $m d m 2$ gene is induced by active wt $\mathrm{p} 53$, through a p53-responsive promoter $\left(\mathrm{P}_{2}\right)$ that resides within intron I of this gene (33-37). In conjunction, this defines an autoregulatory loop whereby the activation of $\mathrm{p} 53$ results in enhanced transcription of the $m d m 2$ gene, which then leads to production of $\mathrm{Mdm} 2$ protein and consequent inactivation of $\mathrm{p} 53$ through proteinprotein interactions $(33,35,38)$.

The inactivation of $\mathrm{p} 53$ by $\mathrm{Mdm} 2$ is achieved through multiple molecular mechanisms. The fact that the Mdm2-binding domain of $\mathrm{p} 53$ overlaps p53's transcriptional activation domain (TAD) results in physical blocking of the interaction between the p53 TAD and critical transcription associated proteins; consequently, the Mdm2-bound form of $\mathrm{p} 53$ is expected to be transcriptionally inactive $(31,39-41)$. Moreover, Mdm2 inhibits p53 not only by concealing its $\mathrm{TAD}$, but also through exerting a direct repressor effect on basal transcription from $\mathrm{p} 53$-responsive promoters (42), presumably through physical interaction with components of the general transcription machinery $(42,43)$. This dual mechanism probably assures efficient inactivation of p53-dependent transcription by Mdm2.

Further insight into the intricacies of the p53-Mdm2 autoregulatory feedback loop came through the finding that the binding of $\mathrm{Mdm} 2$ to p53 results in the targeting of p53 to ubiquitination and subsequent proteasomal degradation $(44,45)$. Thus, Mdm2 can down-regulate p53 function not only through blocking its transcriptional activity, but actually also through directly eliminating it from the cell. Consistent with this conjecture is the finding that interference with p53-Mdm2 interaction through administration of antibodies or peptides that compete with this interaction results in markedly increased steadystate p53 levels in nonstressed cells (46). A possible mechanistic explanation is offered by experiments demonstrating that, at least in vitro, Mdm2 can act as a ubiquitin protein ligase (E3) specific for p53 (47).

Mdm2 expression is induced in a p53-dependent manner in response to a variety of stress signals, including DNA damage (48-52). Extensive DNA damage may sometimes result in de- layed induction of $\mathrm{Mdm} 2$ protein expression $(48,49)$. This delay is believed to provide p53 with an extended time window, in which it can continue to function without being subject to inhibition by the induced Mdm2. At later times, presumably when the stress has been successfully resolved (e.g., through DNA repair), Mdm2 eventually becomes induced, leading to inactivation of the accumulated p53 and termination of the p53 signal $(48,51)$. Although this model is very appealing, it holds only for a subset of circumstances. In other situations of extended stress Mdm2 does get induced rapidly; yet p53 remains constitutively active under those conditions, presumably through post-translational mechanisms that render it immune to Mdm2mediated inhibition (see below).

Tight temporal and spatial regulation of cellular p53 activity may further be achieved through the fact that Mdm2 itself is a short-lived protein (20), also subject to degradation by the ubiquitin-proteasome pathway (53). Thus, once the stress signal has been successfully taken care of, both p53 and Mdm2 can be rapidly cleared through a similar proteolytic mechanism. This will allow a prompt return of the cell to its nonstressed ground state, without compromising the ability of the p53 response to be triggered immediately again should another stress signal be delivered.

It is of note that the $m d m 2$ transcripts induced by activated $\mathrm{p} 53$, which originate in the $\mathrm{P} 2$ promoter, differ from those expressed from the Pl promoter under basal conditions in a p53independent manner $(36,50)$. The P2-derived transcripts have a shorter 5' UTR and are more efficiently translated, which may facilitate the rapid inactivation of p53 once $m d m 2$ gene expression is induced.

The crystal structure of the N-terminal domain of Mdm2 bound to a short $\mathrm{p} 53$ segment reveals that Mdm2 has a deep hydrophobic cleft into which p53 binds as an amphipathic $\alpha$-helix (54). The interface relies on van der Waals interactions involving primarily the hydrophobic and aromatic amino acids Phe19, Trp24, and Leu26 of $\mathrm{p} 53$, and on the steric complementarity between the Mdm2 cleft and the p53 helix. The nature of these tight interactions, also supported by earlier mutational analysis $(40,41)$, offers clues to potential therapeutic intervention and p53 activation.

Mdm2 binds to $\mathrm{p} 53$ preferentially when the latter is present as a tetramer (55). This may serve to ensure that in the absence of stress 
Mdm2 will not cause a complete elimination of cellular p53 and that there will always be a small reservoir of (possibly monomeric) p 53 molecules ready to be rapidly activated by incoming signals. Recently, it was shown that the C-terminal part of p53, including the dimerization domain, is important for Mdm2-targeted degradation (56). This pertains not only to the $\mathrm{p} 53$ oligomerization domain itself, predicted to be required for efficient $\mathrm{Mdm} 2$ binding, but also to the more extreme C-terminal portion of $\mathrm{p} 53$, which is not part of the oligomerization domain. The latter might be due to the presence of multiple lysine residues within this region of $\mathrm{p} 53$, which may serve as sites for Mdm2-directed ubiquitination. Alternatively, since the extreme $\mathrm{C}$ terminus has a critical role in the allosteric regulation of p53 (reviewed in ref. 57), it is conceivable that such regulation may be an important determinant in the ability of p53 to serve as a target for Mdm2promoted degradation.

As mentioned earlier, Mdm2 was shown capable of shuttling between the nucleus and the cytoplasm. This shuttling, while p53-independent, appears to be required for the ability of Mdm2 to promote the degradation of $\mathrm{p} 53$ (27). Recent work has demonstrated directly that treatment of cells with leptomycin B (LMB), which blocks nuclear export and prevents the shuttling of Mdm2 from the nucleus into the cytoplasm, effectively abrogates Mdm2-mediated p53 degradation and leads to nuclear accumulation of active p53 (58). This finding supports the importance of $\mathrm{Mdm} 2$ nucleocytoplasmic shuttling for p53 proteolysis. Nevertheless, this does not necessarily prove that p53 can be exported from the nucleus only in complex with Mdm2. In fact, LMB is expected to block the nuclear export of many proteins. Hence, it is equally likely that p53 can also translocate into the cytoplasm without the help of Mdm2, either on its own or in complex with other proteins, and become targeted for proteolysis upon encountering Mdm2 in the cytoplasm.

In conclusion, Mdm2 can inactivate p53 both in the nucleus and in the cytoplasm-in the former compartment through blocking p53's transcriptional capacity and in the latter through direct down-modulation of cellular p53 levels.

As expected, interaction of $\mathrm{Mdm} 2$ with $\mathrm{p} 53$ can result not only in inhibition of p53-mediated transactivation but also in inhibition of p53-mediated $G_{1}$ arrest and apoptosis $(51,59,60)$. The actual fraction of total cellular p53 that is bound by
Mdm2 may be an important determinant of the eventual growth characteristics of the cell (61).

The in vivo importance of Mdm2-p53 interactions is underscored by the finding that whereas $m d m 2$ null mice die early in development, mice lacking both $p 53$ and $m d m 2$ ("double knock-outs") are viable and develop quite normally $(62,63)$. This implies that Mdm2 plays a critical role in development through the negative regulation of p53 activity; in the absence of Mdm2 function, p53 presumably becomes aberrantly activated, giving rise to a lethal embryonic phenotype.

\section{Post-translational Regulation of Mdm2}

There is growing evidence that many aspects of p53 activity are regulated through post-translational modifications, including phosphorylation and acetylation (reviewed in ref. 57). In particular, phosphorylation of p53 on serine 15 was shown to inhibit its interaction with $\mathrm{Mdm} 2$ in vitro (64), and this mechanism may be responsible in part for the accumulation of stabilized p53 in cells exposed to DNA damage (65). Recent evidence indicates that this site is phosphorylated by the DNA damage-induced ATM kinase $(66,67)$. An involvement has also been suggested for the DNA-dependent protein kinase [DNAPK; (68)], which very effectively phosphorylates this residue in vitro (64).

Mdm2 is also a phosphoprotein $(30,69)$. Hence, it is conceivable that its interaction with p53 may be regulated through phosphorylation not only of p53 but also of Mdm2 itself. In fact, Mdm2 harbors many putative phosphorylation sites for a variety of different protein kinases (5). Moreover, Mdm2 was shown to be phosphorylated in vitro by casein kinase 2 [CK2; (70)], as well as DNA-PK (71). Importantly, in vitro phosphorylation of Mdm2 by DNA-PK prevents it from interacting with p53 (71). This is in line with a model where, upon cellular exposure to stress, both $\mathrm{p} 53$ and $\mathrm{Mdm} 2$ become modified in a manner that interferes with their ability to bind each other, thus leading to stabilization and biochemical activation of $\mathrm{p} 53$. The model predicts that upon recovery from stress, the relevant protein kinases will lose their activity and thereby allow Mdm2 to bind efficiently to p53 and promote its inactivation and rapid degradation. It should be stressed, however, that there is presently no evidence that DNA-PK indeed phos- 
phorylates Mdm2 in vivo. It is also worth noting that Mdm2 was shown to be stabilized and acquire an altered phosphorylation pattern in cells infected or transformed by SV40 (72).

In conclusion, the nature of the kinases that actually modify Mdm2 within living cells and the regulatory significance of such modifications remain to be elucidated. Given the obvious importance of this issue, significant progress is likely to be achieved within the near future.

\section{Mdm2-p53 Interactions: Potential Target for Therapeutic Intervention?}

Many years ago, Oliner et al. (31) suggested that disruption of p53-Mdm2 interactions may bear potential therapeutic promise. In principle, when achieved in tumor cells expressing excess Mdm2 together with endogenous wt p53, such intervention may release p53 from the inhibitory action of $\mathrm{Mdm} 2$ and lead to reconstitution of cancer-inhibitory p53 function. This notion has been explored recently by Lane and co-workers, employing primarily synthetic Mdm2-binding peptides $(46,73,74)$. One successful approach was based on the insertion of such peptide, through recombinant DNA manipulation, into the active site of thioredoxin. When introduced into wt p53-containing cells, the recombinant protein led to accumulation of endogenous p53, activation of p53-dependent transcription, and eventually cell cycle arrest (46). Another approach aimed at inhibition of Mdm2-p53 interactions employed $m d m 2$ antisense oligonucleotides (75). In that case down-modulation of $\mathrm{Mdm} 2$ resulted in p53-inducible gene expression, followed by apoptosis. Moreover, this activation of p53 was further enhanced by exposure to DNA damage (75). This provides a rational basis for hopes to increase the response of tumor cells to cancer therapy through elimination of the p53-inhibitory effects of their endogenous Mdm2.

Similarly, microinjection of an anti-Mdm2 antibody that disrupts Mdm2-p53 interaction gave rise to increased p53 protein levels in a tumorigenic cell line expressing functional wt p53 (76). However, a similar study with the same antibody revealed that normal cells also responded by activation of their endogenous p53 (77). This raises a concern that complete abrogation of Mdm2-p53 interactions may also achieve the apoptotic demise of critical stem cell populations-a problem routinely encountered with conventional anti-cancer therapy. The extent of potential risk can be assessed properly only through studying the effect of $M d m 2$ inactivation in a wide range of normal tissues under physiological conditions.

An alternative experimental approach is suggested by the observation that a synthetic peptide derived from $\mathrm{Mdm} 2$ can stimulate autoreactive cytotoxic $\mathrm{T}$ lymphocytes (CTL) that recognize cells expressing endogenous $\mathrm{Mdm} 2$ (78). If in vivo such CTLs can preferentially target cells that overexpress Mdm2, this could provide a means for the selective killing of certain types of tumor cells.

\section{Protein Partners of Mdm2: Who Else Besides p53?}

Although p53 remains the most prominent Mdm2 interaction partner, both biochemically and biologically, there is a growing list of additional proteins that Mdm2 can bind and possibly regulate through this binding. The study of such interactions and of their interplay with Mdm2p53 interactions is still at an early stage.

Mdm2 inhibits not only the antiproliferative effect of p53 but also that of the retinoblastoma gene product, $\mathrm{pRb}$. Mdm2 can bind $\mathrm{pRb}$ and prevent the induction of pRb-mediated $G_{1}$ cell cycle arrest (79). In addition, Mdm2 can also interact directly with the pRb-regulated transcription factor E2F1/DP1, resulting in stimulation of S-phase progression (80). Mdm2 can thus augment E2Fl/DP1-dependent transactivation through multiple mechanisms. The consequent enhancement of S-phase entry is in line with the oncogenic nature of $\mathrm{Mdm} 2$.

The biochemical interaction of Mdm2 with E2Fl prompted attempts to look for a possible effect of Mdm2 on E2F1-induced apoptosis. While E2Fl-induced apoptosis was not affected by Mdm2 in a $p 53-1-, R b-1-$ background (81), such apoptosis was indeed inhibited by Mdm2 when the process was p53-dependent (82). However, conclusive interpretation of these data is hampered by the fact that E2F1 and DPl were reported to interact not only with $\mathrm{Mdm} 2$ and pRb but also with p53 itself $(83,84)$.

Another recently described provocative interaction of $\mathrm{Mdm} 2$ is with the cell-fate regulator protein Numb (85). This association promotes translocation of Numb into the nucleus and leads 
to a reduction in Numb steady-state levels, through a mechanism that appears to be similar to Mdm2-mediated p53 degradation (85). This raises the possibility that $\mathrm{Mdm} 2$ may regulate the stability of a larger panel of regulatory proteins; identification of additional targets for Mdm2-directed proteolysis might provide new insight into the biological roles of Mdm2.

Unlike p53, the degradation of its homolog p73 is not promoted by $\mathrm{Mdm} 2$; in fact, $\mathrm{Mdm} 2$ overexpression may even lead to an increase in cellular p73 levels (86). Nevertheless, Mdm2 does bind to p73 and inhibits its transcriptional activity. This is apparently achieved through interference with the binding between p73 and p300, a critical co-activator required for optimal transcriptional activity of both p53 and p73 (86). Hence, the autoregulatory loop appears to apply to at least several members of the recently enlarged p53 family, although the mechanisms may be different in each case. In any event, the outcome of deregulation is likely to be similar: abrogation of proper growth arrest and of apoptotic responses (86), facilitating the development of cancer.

Perhaps the most revealing Mdm2-related finding in 1998 relates to the pl9ARF (mouse)/ pl4ARF (human) tumor suppressor protein. In earlier work, it was found that this Alternative Reading Frame product of the pl6 tumor suppressor locus is a potent cell cycle inhibitor (87). Subsequent work revealed that ARF can in fact bind Mdm2 (88-91). In addition, ARF can bind directly to p53, and formation of p53/Mdm2/ ARF ternary complexes has also been described $(89,90)$. The physical interaction of ARF with Mdm2 blocks Mdm2-mediated p53 degradation and restores p53-mediated transactivation (88). Hence, through its effects on Mdm2 (as well as directly through p53 binding) ARF can serve as an upstream activator of $\mathrm{p} 53$. In line with the model where p19 acts upstream of p53, its overexpression results in growth arrest on a wt p53 background but not in p53 null cells (90).

The ARF-binding domain of Mdm2 does not overlap the p53-binding domain (88-90); this might explain the ability to form ternary complexes, presumably assembled around Mdm2. An enigmatic issue is how such complexes retain the biochemical activities of $\mathrm{p} 53$, given that the p53 TAD is expected to be blocked by the associated $\mathrm{Mdm} 2$.

Like with many other aspects of p53-related regulatory circuits, the ARF-Mdm2 story is not so simple. While being up-regulated by
ARF, p53 itself actually down-regulates ARF expression (91). This implies the existence of an additional negative autoregulatory loop, somewhat akin to the p53-Mdm2 loop. Furthermore, production of ARF mRNA is positively regulated by the E2Fl transcription factor (92). Since Mdm2 has been proposed to induce E2F activity (see above), this raises the testable prediction that $\mathrm{Mdm} 2$ should also augment ARF expression (see Fig. 2).

Several recent reports open the road to a better understanding of how aberrant oncogene activation triggers $\mathrm{p} 53$ activation. The cellular myc protein, as well as the adenovirus ElA oncoprotein and an oncogenic activated ras, are potent inducers of cell transformation but also activators of p53. As it turns out, the three oncoproteins induce strongly ARF expression and p53 stabilization (93-95). The positive regulation of p53 through ARF may serve as a fail-safe device for counteracting the harmful effects of unscheduled oncogene activation. The molecular mechanism for oncogene-initiated, ARF-mediated p53 activation is clearly distinct from that utilized by DNA damage; this is indicated by the fact that, unlike signals emanating from damaged DNA, activation of p53 by the oncoprotein/ARF upstream pathway does not involve phosphorylation of p53 on serine 15 (93).

Like ARF, the transcriptional coactivator p300 is also capable of direct interaction with both Mdm2 and p53 (96).p300 and the closely related CBP bind $\mathrm{p} 53$ and are required for its efficient transcriptional activity (97-100). On the other hand, the interaction of Mdm2 with p300 contributes to the p53-destabilizing action of Mdm2. Thus, an Mdm2 mutant capable of binding $\mathrm{p} 53$ but not $\mathrm{p} 300$ is defective in $\mathrm{p} 53$ degradation (96). Similarly, a p53 mutant unable to bind p300 is resistant to Mdm2-mediated degradation. This suggests that the interplay between $\mathrm{Mdm} 2$, p53, and p300 can regulate p53 activity by either allowing effective p300-dependent $p 53$ transcriptional activity or targeting p53 for rapid proteasomal degradation.

Another facet of this story is provided by the observation that while $\mathrm{p} 300$ is generally required for optimal p53-mediated transactivation, it is particularly crucial for the activation of the $m d m 2$ gene (101). Consequently, the viral E1A oncoprotein, which sequesters $\mathrm{p} 300$, interferes selectively with $m d m 2$ induction by $\mathrm{p} 53$. The failure to produce $\mathrm{Mdm} 2$ protein results in $\mathrm{p} 53$ stabiliza- 


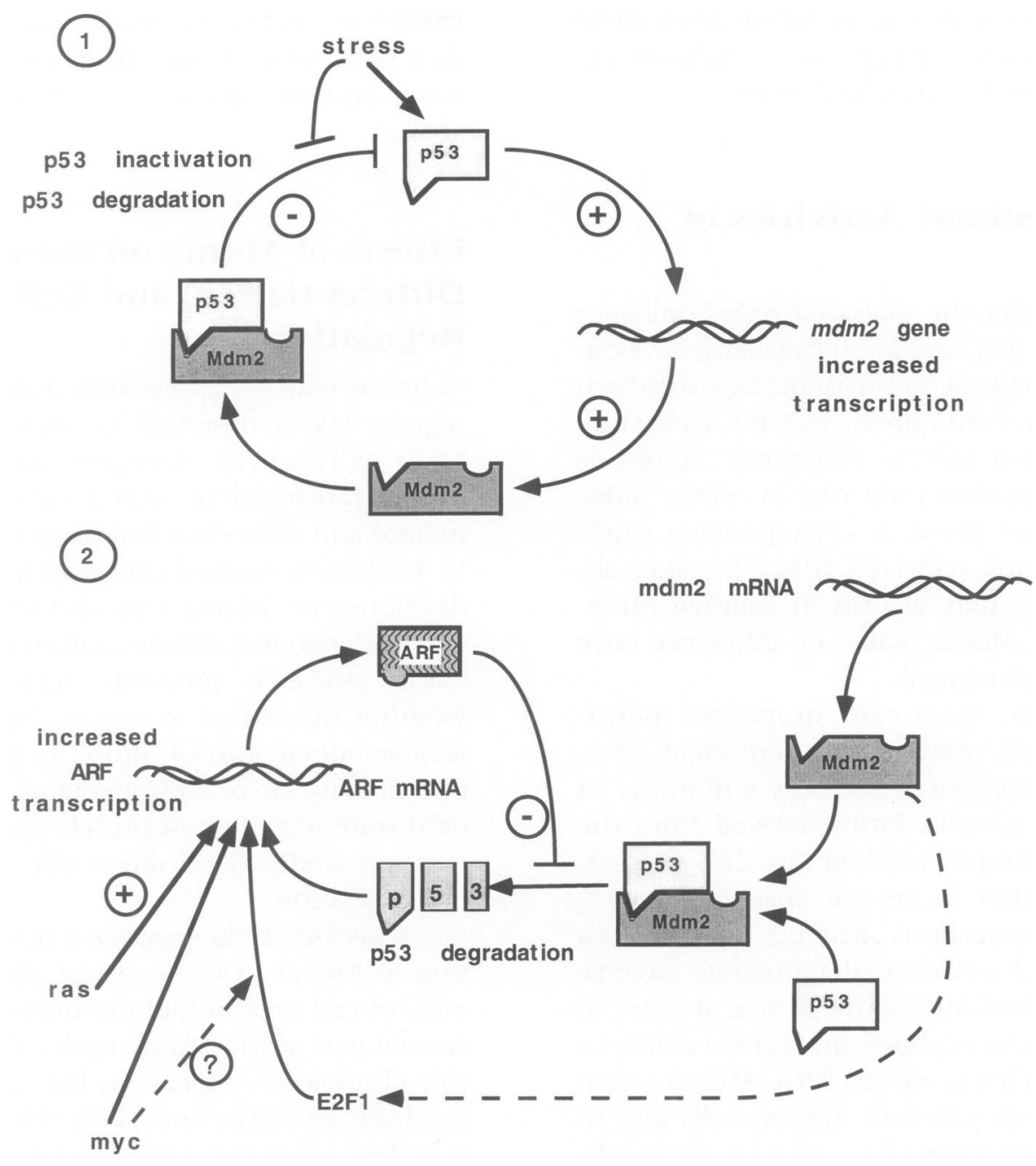

Fig. 2. The "Mdm2 loops." Depicted are two possible autoregulatory loops whose existence is supported by the data discussed in this minireview. These loops are not mutually exclusive; in fact, they most probably are integrated into each other, and are depicted as separate only for the sake of simplicity. In loop 1 (the "traditional" loop), activation of p53 is proposed to induce $m d m 2$ transcription and production of $\mathrm{Mdm} 2$ protein, which then binds to p53, inactivates it, and targets it for degradation, thereby restraining excess p53 activity. Stress signals may allow p53 activation and accumulation through interfering with the inhibitory effects of $\mathrm{Mdm} 2$ on

tion and accumulation, culminating in p53-dependent apoptosis (101). In this context, it was indeed noted that expression of extra p300 could rescue cells from p53-mediated apoptosis, presumably through induction of $\mathrm{Mdm} 2$ production and subsequent p53 inactivation (101).

Figure 2 depicts two possible feedback circuits suggested by these recent findings. It is clear that the situation is not as simple as depicted; p53. In loop 2, augmented Mdm2 protein production (e.g., through gene amplification, translational mechanisms, etc.) is proposed to lead to down-regulation of $\mathrm{p} 53$ protein. This will relieve the inhibitory effect of p53 on ARF transcription and, in conjunction with the Mdm2-mediated augmentation of E2Fl activity, will result in enhanced ARF expression, and consequently in inhibition of Mdm2 function through ARF-Mdm2 protein interactions. The nonoverlapping binding sites for p53 and for ARF on the $\mathrm{Mdm} 2$ molecule are indicated by different shapes. See text for further details.

within a living cell, these and additional "cycles" are part of one complex network, which most certainly includes many other critical regulatory proteins.

Altogether, one starts to get a glimpse of a complex network of closely interwoven, regulatory feedback loops involving as central players p53, Mdm2, and ARF, as well as several of their interaction partners. How the actual cellular 
phenotype is eventually determined, given these sometimes counteracting circuits, remains an extremely important, unresolved issue.

\section{p53-Independent Activities of Mdm2}

As discussed earlier, the analysis of $m d m 2$ null mice argues strongly that, at least during early development, the most critical role of Mdm2 has to do with p53 modulation. Furthermore, $p 53$ null, $m d m 2$ null double knock-out mouse embryonic fibroblasts (MEFs) exhibit growth properties in culture indistinguishable from those of corresponding single knock-out $p 53$ null cells $(102,103)$. The latter observation implies that, at least in cultured MEFs, the presence of $\mathrm{Mdm} 2$ makes no difference once p53 function is abrogated.

Nevertheless, there exist numerous indications that Mdm2 may possess additional, p53independent functions. First, only a minority of the alternative protein forms derived from the $m d m 2$ gene retain $\mathrm{p} 53$ binding (20-22), suggesting that the other forms are engaged in p53independent interactions. Second, several lines of experimental evidence demonstrate diverse biological effects of $\mathrm{Mdm} 2$ in the total absence of p53. In addition to its above-mentioned ability to bind other proteins as well as RNA, Mdm2 is also able to transform p53-null human cells and to overcome a p107-induced $G_{1}$ arrest in such cells (104). Moreover, the effects of overexpressed Mdm2 on mammary gland development and tumorigenicity observed by Lundgren et al. (7) could be seen even on the background of $p 53-$ null mice.

The potential importance of p53-independent activities of $\mathrm{Mdm} 2$ is highlighted by the recent work of Sun et al. (105). A screen for genes capable of conferring resistance to the antiproliferative effects of transforming growth factor $\beta$ (TGF- $\beta$ ) yielded repeatedly cDNA clones corresponding to Mdm2. Furthermore, overexpression of Mdm2 could rescue cells from TGF$\beta$-mediated growth inhibition. Importantly, this effect did not require the presence of functional p53; rather, it was exerted through inactivation of $\mathrm{pRb}$ and augmentation of the activity and overall protein levels of E2Fl (105). Abrogation of TGF- $\beta$ responsiveness may thus contribute to the oncogenic activation of Mdm2. Moreover, since enhanced TGF- $\beta$ resistance is frequently encountered as tumors become metastatic, it is conceivable that $\mathrm{Mdm} 2$ expression may also con- tribute to metastatic properties. It is expected that $\mathrm{p} 53$-independent effects of Mdm2 will receive growing attention within the next few years.

\section{Effects of Mdm2 on Development, Differentiation, and Cell Cycle Regulation}

Mdm2 is widely expressed in many tissues, with highest levels observed in testis, muscle, and brain $(5,106,107)$. Aberrant overexpression of Mdm2 can interfere with a variety of developmental and differentiation processes. In addition to its aforementioned effects on mammary gland development, Mdm2 was also shown to inhibit MyoD-dependent differentiation of mouse myoblasts (108). It presently remains unknown whether this is due to one of the reported molecular interactions of $\mathrm{Mdm} 2$ (e.g., inhibition of p53 activity or of pRb-mediated MyoD-dependent transactivation of muscle-specific genes) or to a yet undescribed direct effect of $\mathrm{Mdm} 2$ on differentiation.

A recent study suggests a positive contribution of $M d m 2$ to $G_{0} / G_{1}$ arrest, due to the presence of cell cycle inhibitory domains within the central part of the Mdm2 molecule (109). While this observation appears at first glance counterintuitive, given the oncogenic effects of $\mathrm{Mdm} 2$, it is in fact consistent with the fact that many investigators have encountered great difficulties in obtaining $\mathrm{Mdm} 2$ overexpression through stable transfection of a variety of cell types. The intact Mdm2 protein may thus contain a "self-restraining" domain [mapped by Brown et al. to the central portion of the protein (109)] which restricts its potential oncogenic effects in case it becomes aberrantly overexpressed. This possibility echoes a familiar theme, already introduced in the context of other, better studied oncogenes: the existence of protective "fail-safe" mechanisms that couple a growth-inhibitory (e.g., in the case of ras) or pro-apoptotic (e.g., myc) effect with deregulated oncogene action. It is tempting to speculate that the Mdm2 "self-restraining" domain is the same one that is responsible for ARF binding, so that its loss now renders Mdm2 immune to inhibition by ARF and thus constitutively active and more effectively oncogenic. The existence of a plethora of alternative Mdm2 polypeptides may be one way in which forms with different degrees of built-in "restraint" are generated. This notion is supported by the data of 


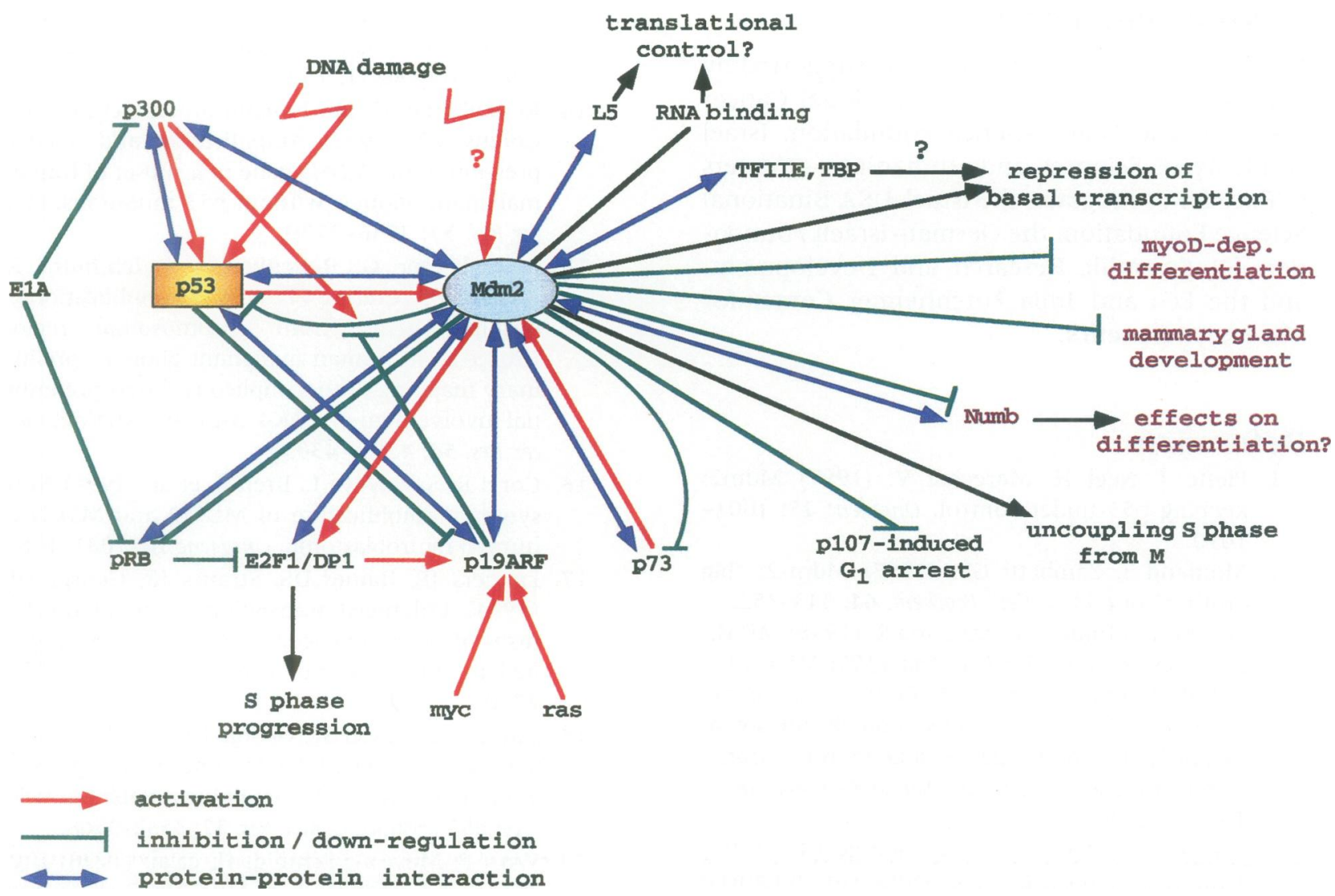

Fig. 3. Schematic model depicting regulatory interactions between Mdm2 and other proteins, as well as possible functional consequences of such interactions. See text for details.

Sigalas et al. (22), based on the analysis of human tumors.

\section{Family Connections}

A recent excitement in the $\mathrm{p} 53$ field has been the discovery of several related genes and proteins, which together now comprise a small p53 gene family. In the case of $m d m 2$, a "cousin" has already been described earlier and given the name $m d m x$ (106). The Mdmx protein is structurally similar to Mdm2, especially in the $\mathrm{N}$-terminal p53-binding domain and in the C-terminal part. Identified by virtue of its association with p53 (106), Mdmx resembles Mdm2 in that it can bind p53 and inhibit p53-mediated transactivation. However, Mdmx expression is not induced by DNA damage (106). It remains to be established whether Mdmx can also target $\mathrm{p} 53$ for proteasomal degradation. It is of note that in both mouse and humans, $m d m x$ mRNA is expressed in all tissues tested $(106,110)$, raising the possibility that Mdmx may provide a constitutive "buffer" for p53, minimizing the latter's biochemical effects as long as p53 is not induced well above its low basal levels. Obviously, a better understanding of the roles of $\mathrm{Mdmx}$, along with the possible existence of additional $m d m 2$ family members, awaits further studies.

\section{Conclusions}

Until recently, the interplay between p53 and Mdm2 was perhaps the only part in the complex p53 picture that was believed to be simple and satisfactorily understood. Not so anymore. Figure 3 depicts the complex network of regulatory interactions in which $\mathrm{Mdm} 2$ is engaged. As Mdm2 is becoming implicated in more and more pathways, and on its way is picking a growing company of new protein partners, there is an increased realization that the $\mathrm{Mdm} 2$ story is likely to be as complicated as that of p53, and, we hope, equally exciting. 


\section{Acknowledgments}

Work in the authors' laboratory is supported by grant ROl CA 40099 from the National Cancer Institute, The Israel Science Foundation, Israel Academy of Sciences and Humanities-Centers of Excellence Program, the Israel-USA Binational Science Foundation, the German-Israeli Foundation for Scientific Research and Development, and the Leo and Julia Forchheimer Center for Molecular Genetics.

\section{References}

1. Piette J, Neel H, Marechal V. (1997) Mdm2: keeping p53 under control. Oncogene 15: 10011010.

2. Momand J, Zambetti GP. (1997) Mdm-2: “big brother" of p53. J. Cell. Biochem. 64: 343-352.

3. Lozano G, Montes De Oca Luna R. (1998) MDM2 function. Biochim. Biophys. Acta 1377: M55-59.

4. Cahilly-Snyder L, Yang FT, Francke U, George DL. (1987) Molecular analysis and chromosomal mapping of amplified genes isolated from a transformed mouse 3T3 cell line. Somat. Cell Mol. Genet. 13: $235-244$

5. Fakharzadeh SS, Trusko SP, George DL. (1991) Tumorigenic potential associated with enhanced expression of a gene that is amplified in a mouse tumor cell line. EMBO J. 10: 1565-1569.

6. Finlay CA. (1993) The $m d m-2$ oncogene can overcome wild-type p53 suppression of transformed cell growth. Mol. Cell. Biol. 13: 301-306.

7. Lundgren K, Montes De Oca Luna R, McNeill YB, et al. (1997) Targeted expression of MDM2 uncouples $S$ phase from mitosis and inhibits mammary gland development independent of p53. Genes Dev. 11: 714-725.

8. Momand J, Jung D, Wilczynski S, Niland J. (1998) The MDM2 gene amplification database. Nucl. Acids Res. 26: 3453-3459.

9. Oliner JD, Kinzler KW, Meltzer PS, George DL, Vogelstein B. (1992) Amplification of a gene encoding a p53-associated protein in human sarcomas [see comments]. Nature 358: 80-83.

10. Leach FS, Tokino T, Meltzer P, et al. (1993) p53 Mutation and MDM2 amplification in human soft tissue sarcomas. Cancer Res. 2231-2234.

11. Cordon-Cardo C, Latres E, Drobnjak M, et al. (1994) Molecular abnormalities of $m d m 2$ and $p 53$ genes in adult soft tissue sarcomas. Cancer Res. 54: 794-799.

12. Ladanyi $M$, Cha $C$, Lewis $R$, Jhanwar SC, Huvos AG, Healey JH. (1993) MDM2 gene amplification in metastatic osteosarcoma. Cancer Res. 53: 1618.

13. Shibagaki I, Tanaka H, Shimada Y, et al. (1995) p53 mutation, Murine Double Minute 2 amplification, and human papillomavirus infection are frequently involved but not associated with each other in esophageal squamous cell carcinoma. Clin. Cancer Res. 1: 769-773.

14. Reifenberger G, Liu L, Ichimura K, Schmidt EE, Collins VP. (1993) Amplification and overexpression of the MDM2 gene in a subset of human malignant gliomas without p53 mutations. Cancer Res. 53: 2736-2739.

15. Reifenberger G, Reifenberger J, Ichimura K, Meltzer PS, Collins VP. (1994) Amplification of multiple genes from chromosomal region 12q13-14 in human malignant gliomas: preliminary mapping of the amplicons shows preferential involvement of CDK4, SAS, and MDM2. Cancer Res. 54: 4299-4303.

16. Corvi R, Savelyeva L, Breit S, et al. (1995) Nonsyntenic amplification of MDM2 and MYCN in human neuroblastoma. Oncogene 10: 1081-1086.

17. Landers JE, Haines DS, Strauss JR, George DL. (1994) Enhanced translation: a novel mechanism of $m d m 2$ oncogene overexpression identified in human tumor cells. Oncogene 9: 27452750.

18. Landers JE, Cassel SL, George DL. (1997) Translational enhancement of $m d m 2$ oncogene expression in human tumor cells containing a stabilized wildtype p53 protein. Cancer Res. 57: 3562-3568.

19. Wurl P, Meye A, Schmidt H, et al. (1998) High prognostic significance of $\mathrm{Mdm} 2 / \mathrm{p} 53$ co-overexpression in soft tissue sarcomas of the extremities. Oncogene 16: 1183-1185.

20. Olson DC, Marechal V, Momand J, Chen J, Romocki C, Levine AJ. (1993) Identification and characterization of multiple mdm-2 proteins and mdm-2-p53 protein complexes. Oncogene 8: 2353-2360.

21. Haines DS, Landers JE, Engle LJ, George DL. (1994) Physical and functional interaction between wild-type p53 and mdm2 proteins. Mol. Cell. Biol. 14: 1171-1178.

22. Sigalas I, Calvert AH, Anderson JJ, Neal DE, Lunec J. (1996) Alternatively spliced mdm2 transcripts with loss of p53 binding domain sequences: transforming ability and frequent detection in human cancer. Nat. Med. 2: 912-917.

23. Marechal V, Elenbaas B, Taneyhill L, et al. (1997) Conservation of structural domains and biochemical activities of the MDM2 protein from Xenopus laevis. Oncogene 14: 1427-1433.

24. Elenbaas B, Dobbelstein $M$, Roth J, Shenk $T$, Levine AJ. (1996) The MDM2 oncoprotein binds specifically to RNA through its RING finger domain. Mol. Med. 2: 439-451.

25. Marechal V, Elenbaas B, Piette J, Nicolas JC, Levine AJ. (1994) The ribosomal L5 protein is associated with mdm-2 and mdm-2-p53 complexes. Mol. Cell. Biol. 14: 7414-7420.

26. Boddy MN, Freemont PS, Borden KL. (1994) The p53-associated protein MDM2 contains a newly 
characterized zinc-binding domain called the RING finger. Trends Biochem. Sci. 19: 198-199.

27. Roth J, Dobbelstein M, Freedman DA, Shenk T, Levine AJ. (1998) Nucleo-cytoplasmic shuttling of the hdm2 oncoprotein regulates the levels of the $\mathrm{p} 53$ protein via a pathway used by the human immunodeficiency virus rev protein. $E M B O$ J. 17: 554-564.

28. Chen L, Marechal V, Moreau J, Levine AJ, Chen J. (1997) Proteolytic cleavage of the mdm2 oncoprotein during apoptosis. J. Biol. Chem. 272: 22966-22973.

29. Erhardt P, Tomaselli KJ, Cooper GM. (1997) Identification of the MDM2 oncoprotein as a substrate for CPP32-like apoptotic proteases. J. Biol. Chem. 272: 15049-15052.

30. Momand J, Zambetti GP, Olson DC, George D, Levine AJ. (1992) The mdm-2 oncogene product forms a complex with the $\mathrm{p} 53$ protein and inhibits p53-mediated transactivation. Cell 69: 12371245.

31. Oliner JD, Pietenpol JA, Thiagalingam S, Gyuris J, Kinzler KW, Vogelstein B. (1993) Oncoprotein MDM2 conceals the activation domain of tumour suppressor p53. Nature 362: 857-860.

32. Chen J, Lin J, Levine AJ. (1995) Regulation of transcription functions of the p53 tumor suppressor by the $m d m-2$ oncogene. Mol. Med. 1: 142-152.

33. Barak Y, Juven T, Haffner R, Oren M. (1993) mdm2 expression is induced by wild-type p53 activity. EMBO J. 12: 461-468.

34. Juven T, Barak Y, Zauberman A, George DL, Oren M. (1993) Wild-type p53 can mediate sequence-specific transactivation of an internal promoter within the $m d m 2$ gene. Oncogene 8: 3411-3416.

35. Wu X, Bayle JH, Olson D, Levine AJ. (1993) The p53-mdm-2 autoregulatory feedback loop. Genes Dev. 7: 1126-1132.

36. Barak Y, Gottlieb E, Juven-Gershon T, Oren M. (1994) Regulation of mdm2 expression by $\mathrm{p} 53$ : alternative promoters produce transcripts with nonidentical translation potential. Genes Dev. 8: 1739-1749.

37. Zauberman A, Flusberg D, Haupt Y, Barak Y, Oren M. (1995) A functional p53-responsive intronic promoter is contained within the human mdm2 gene. Nucl. Acids Res. 23: 2584-2592.

38. Picksley SM, Lane DP. (1993) The p53-mdm2 autoregulatory feedback loop: a paradigm for the regulation of growth control by p53? Bioessays 15: 689-690.

39. Chen J, Marechal V, Levine AJ. (1993) Mapping of the p53 and mdm-2 interaction domains. Mol. Cell. Biol. 13: 4107-4114.

40. Lin J, Chen J, Elenbaas B, Levine AJ. (1994) Several hydrophobic amino acids in the p53 amino-terminal domain are required for transcriptional activation, binding to $\mathrm{mdm}-2$ and the ad- enovirus 5 ElB 55-kD protein. Genes Dev. 8: 1235-1246.

41. Picksley SM, Vojtesek B, Sparks A, Lane DP. (1994) Immunochemical analysis of the interaction of p53 with MDM2-fine mapping of the MDM2 binding site on p53 using synthetic peptides. Oncogene 9: 2523-2529.

42. Thut CJ, Goodrich JA, Tjian R. (1997) Repression of p53-mediated transcription by MDM2: a dual mechanism. Genes Dev. 11: 1974-1986.

43. Leng P, Brown DR, Deb S, Deb SP. (1995) Human oncoprotein MDM2 interacts with the TATA-binding protein in vitro and in vivo. Int. $J$. Oncology 6: 251-259.

44. Haupt Y, Maya R, Kazaz A, Oren M. (1997) Mdm2 promotes the rapid degradation of $\mathrm{p} 53$. Nature 387: 296-299.

45. Kubbutat MH, Jones SN, Vousden KH. (1997) Regulation of p53 stability by Mdm2. Nature 387: 299-303.

46. Bottger A, Bottger V, Sparks A, Liu WL, Howard SF, Lane DP. (1997) Design of a synthetic Mdm2binding mini protein that activates the p53 response in vivo. Curr. Biol. 7: 860-869.

47. Honda R, Tanaka H, Yasuda H. (1997) Oncoprotein MDM2 is a ubiquitin ligase E3 for tumor suppressor p53. FEBS Lett. 420: 25-27.

48. Perry ME, Piette J, Zawadzki JA, Harvey D, Levine AJ. (1993) The $m d m-2$ gene is induced in response to UV light in a p53-dependent manner. Proc. Natl. Acad. Sci. U.S.A. 90: 11623-1 1627.

49. $\mathrm{Wu}$ L, Levine AJ. (1997) Differential regulation of the p21/WAF-1 and mdm2 genes after highdose UV irradiation: p53-dependent and p53independent regulation of the $m d m 2$ gene. Mol. Med. 3: 441-451.

50. Saucedo LJ, Carstens BP, Seavey SE, Albee LD, Perry ME. (1998) Regulation of transcriptional activation of $m d m 2$ gene by p53 in response to UV radiation. Cell Growth Differ. 9: 119-130.

51. Chen CY, Oliner JD, Zhan Q, Fornace AJ, Vogelstein B, Kastan MB. (1994) Interactions between p53 and MDM2 in a mammalian cell cycle checkpoint pathway. Proc. Natl. Acad. Sci. U.S.A. 91: 2684-2688.

52. Price BD, Park SJ. (1994) DNA damage increases the levels of MDM2 messenger RNA in wtp53 human cells. Cancer Res. 54: 896-899.

53. Chang YC, Lee YS, Tejima T, et al. (1998) mdm 2 and bax, downstream mediators of the p53 response, are degraded by the ubiquitin-proteasome pathway. Cell Growth Differ. 9: 79-84.

54. Kussie PH, Gorina S, Marechal V, et al. (1996) Structure of the MDM2 oncoprotein bound to the p53 tumor suppressor transactivation domain. Science 274: 948-953.

55. Marston NJ, Jenkins JR, Vousden KH. (1995) Oligomerisation of full length p53 contributes to the interaction with mdm 2 but not HPV E6. Oncogene 10: 1709-1715. 
56. Kubbutat M, Ludwig RL, Ashcroft M, Vousden KH. (1998) Regulation of Mdm2-directed degradation by the $\mathrm{C}$ terminus of p53. Mol. Cell. Biol. 18: $5690-5698$.

57. Prives C. (1998) Signaling to p53: breaking the MDM2-p53 circuit. Cell 95: 5-8.

58. Freedman DA, Levine AJ. (1998) Nuclear export is required for degradation of endogenous $\mathrm{p} 53$ by MDM2 and human papillomavirus E6. Mol. Cell. Biol. 18: 7288-7293.

59. Chen J, Wu X, Lin J, Levine AJ. (1996) mdm-2 inhibits the $\mathrm{Gl}$ arrest and apoptosis functions of the p53 tumor suppressor protein. Mol. Cell. Biol. 16: 2445-2452.

60. Haupt Y, Barak Y, Oren M. (1996) Cell typespecific inhibition of p53-mediated apoptosis by mdm2. EMBO J. 15: 1596-1606.

61. Momand J, Zambetti GP. (1996) Analysis of the proportion of $\mathrm{p} 53$ bound to mdm-2 in cells with defined growth characteristics. Oncogene 12: 2279-2289.

62. Montes De Oca Luna R, Wagner DS, Lozano G. (1995) Rescue of early embryonic lethality in $m d m 2$-deficient mice by deletion of p53. Nature 378: 203-206.

63. Jones SN, Roe AE, Donehower LA, Bradley A. (1995) Rescue of embryonic lethality in Mdm2deficient mice by absence of p53. Nature 378: 206-208.

64. Shieh SY, Ikeda M, Taya Y, Prives C. (1997) DNA damage-induced phosphorylation of p53 alleviates inhibition by MDM2. Cell 91: 325-334.

65. Siliciano JD, Canman CE, Taya Y, Sakaguchi K, Appella E, Kastan MB. (1997) DNA damage induces phosphorylation of the amino terminus of p53. Genes Dev. 11: 3471-3481.

66. Banin S, Moyal L, Shieh S, et al. (1998) Enhanced phosphorylation of p53 by ATM in response to DNA damage. Science 281: 1674-1677.

67. Canman CE, Lim DS, Cimprich KA, et al. (1998) Activation of the ATM Kinase by Ionizing Radiation and Phosphorylation of p53. Science 281: 1677-1679.

68. Woo RA, McLure KG, Lees-Miller SP, Rancourt DE, Lee PW. (1998) DNA-dependent protein kinase acts upstream of p53 in response to DNA damage. Nature 394: 700-704.

69. Barak Y, Oren M. (1992) Enhanced binding of a $95 \mathrm{kDa}$ protein to p53 in cells undergoing p53mediated growth arrest. EMBO J. 11: 2115-2121.

70. Guerra B, Gotz C, Wagner P, Montenarh M, Issinger OG. (1997) The carboxy terminus of $p 53$ mimics the polylysine effect of protein kinase CK2-catalyzed MDM2 phosphorylation. Oncogene 14: 2683-2688.

71. Mayo LD, Turchi JJ, Berberich SJ. (1997) Mdm-2 phosphorylation by DNA-dependent protein kinase prevents interaction with p53. Cancer Res. 57: 5013-5016.

72. Henning W, Rohaly G, Kolzau T, Knippschild U,
Maacke H, Deppert W. (1997) MDM2 is a target of simian virus 40 in cellular transformation and during lytic infection. J. Virol. 71: 7609-7618.

73. Bottger V, Bottger A, Howard SF, et al. (1996) Identification of novel mdm2 binding peptides by phage display. Oncogene 13: 2141-2 147.

74. Bottger A, Bottger V, Garcia EC, et al. (1997) Molecular characterization of the hdm2-p53 interaction. J. Mol. Biol. 269: 744-756.

75. Chen L, Agrawal S, Zhou W, Zhang R, Chen J. (1998) Synergistic activation of $p 53$ by inhibition of MDM2 expression and DNA damage. Proc. Natl. Acad. Sci. U.S.A. 95: 195-200.

76. Midgley CA, Lane DP. (1997) p53 protein stability in tumour cells is not determined by mutation but is dependent on Mdm2 binding. Oncogene 15: 1179-1189.

77. Blaydes JP, Wynford-Thomas D. (1998) The proliferation of normal human fibroblasts is dependent upon negative regulation of $\mathrm{p} 53$ function by mdm2. Oncogene 16: 3317-3322.

78. Dahl AM, Beverley PC, Stauss HJ. (1996) A synthetic peptide derived from the tumor-associated protein $\mathrm{mdm} 2$ can stimulate autoreactive, high avidity cytotoxic $\mathrm{T}$ lymphocytes that recognize naturally processed protein. J. Immunol. 157: 239-246.

79. Xiao ZX, Chen J, Levine AJ, et al. (1995) Interaction between the retinoblastoma protein and the oncoprotein MDM2. Nature 375: 694-698.

80. Martin K, Trouche D, Hagemeier C, Sorensen TS, La Thangue N, Kouzarides T. (1995) Stimulation of E2Fl/DPl transcriptional activity by MDM2 oncoprotein. Nature 375: 691-694.

81. Hsieh JK, Fredersdorf S, Kouzarides T, Martin K, Lu X. (1997) E2F1-induced apoptosis requires DNA binding but not transactivation and is inhibited by the retinoblastoma protein through direct interaction. Genes Dev. 11: 1840-1852.

82. Kowalik TF, DeGregori J, Leone G, Jakoi L, Nevins JR. (1998) E2Fl-specific induction of apoptosis and p53 accumulation, which is blocked by Mdm2. Cell Growth Differ. 9: 113-118.

83. O'Connor DJ, Lam EW, Griffin S, et al. (1995) Physical and functional interactions between $\mathrm{p} 53$ and cell cycle co-operating transcription factors, E2F1 and DP1. EMBO J. 14: 6184-6192.

84. Sorensen TS, Girling R, Lee CW, Gannon J, Bandara LR, La Thangue N. (1996) Functional interaction between DP-1 and p53. Mol. Cell. Biol. 16: 5888-5895.

85. Juven-Gershon $\mathrm{T}$, Shifman $\mathrm{O}$, Unger $\mathrm{T}$, Elkeles A, Haupt Y, Oren M. (1998) The Mdm2 oncoprotein interacts with the cell fate regulator numb. Mol. Cell. Biol. 18: 3974-3982.

86. Zeng $X$, Chen L, Jost CA, et al. Mdm2 suppresses p73 function without promoting p73 degradation. Mol. Cell. Biol. (in press).

87. Quelle DE, Zindy F, Ashmun RA, Sherr CJ. (1995) Alternative reading frames of the INK4a 
tumor suppressor gene encode two unrelated proteins capable of inducing cell cycle arrest. Cell 83: 993-1000.

88. Pomerantz J, Schreiber AN, Liegeois NJ, et al. (1998) The Ink4a tumor suppressor gene product, p19Arf, interacts with MDM2 and neutralizes MDM2's inhibition of p53. Cell 92: 713-723.

89. Zhang Y, Xiong Y, Yarbrough WG. (1998) ARF promotes MDM2 degradation and stabilizes p53: ARF-INK4a locus deletion impairs both the $\mathrm{Rb}$ and p53 tumor suppression pathways. Cell 92: 725-734.

90. Kamijo T, Weber JD, Zambetti G, Zindy F, Roussel MF, Sherr CJ. (1998) Functional and physical interactions of the ARF tumor suppressor with p53 and Mdm2. Proc. Natl. Acad. Sci. U.S.A. 95: 8292-8297.

91. Stott FJ, Bates S, James MC, et al. (1998) The alternative product from the human CDKN2A locus, pl4(ARF), participates in a regulatory feedback loop with p53 and MDM2. EMBO J. 17: 5001-5014.

92. Bates S, Phillips AC, Clark PA, et al. (1998) pl4ARF links the tumour suppressors RB and p53. Nature 395: 124-125.

93. de-Stanchina E, McCurrach ME, Zindy F, et al. (1998) ElA signaling to p53 involves the pl9(ARF) tumor suppressor. Genes Dev. 12: 2434-2442.

94. Zindy F, Eischen CM, Randle DH, et al. (1998) Myc signaling via the ARF tumor suppressor regulates p53-dependent apoptosis and immortalization. Genes Dev. 12: 2424-2433.

95. Palmero I, Pantoja C, Serrano M. (1998) pl9ARF links the tumour suppressor p53 to Ras. Nature 395: 125-126.

96. Grossman SR, Perez M, Kung AL, et al. (1998) p300/MDM2 complexes participate in MDM2mediated p53 degradation. Mol. Cell 2: 405-415.

97. Lill NL, Grossman SR, Ginsberg D, DeCaprio J, Livingston DM. (1997) Binding and modulation of p53 by p300/CBP coactivators. Nature 387: 823-827.

98. Gu W, Shi XL, Roeder RG. (1997) Synergistic activation of transcription by CBP and p53. $\mathrm{Na}$ ture 387: 819-823.

99. Avantaggiati ML, Ogryzko V, Gardner K, Giordano A, Levine AS, Kelly K. (1997) Recruitment of p300/CBP in p53-dependent signal pathways. Cell 89: 1175-1 184 .

100. Scolnick DM, Chehab NH, Stavridi ES, et al. (1997) CREB-binding protein and p300/CBP-associated factor are transcriptional coactivators of the p53 tumor suppressor protein. Cancer Res. 57: 3693-3696.

101. Thomas A, White E. (1998) Suppression of the p300-dependent mdm2 negative-feedback loop induces the p53 apoptotic function. Genes Dev. 12: 1975-1985.

102. McMasters KM, Montes De Oca Luna R, Pena JR, Lozano G. (1996) mdm2 deletion does not alter growth characteristics of p53-deficient embryo fibroblasts. Oncogene 13: 1731-1736.

103. Jones SN, Sands AT, Hancock AR, et al. (1996) The tumorigenic potential and cell growth characteristics of $\mathrm{p} 53$-deficient cells are equivalent in the presence or absence of $\mathrm{Mdm} 2$. Proc. Natl. Acad. Sci. U.S.A. 93: 14106-14111.

104. Dubs-Poterszman $M$, Tocque B, Wasylyk B. (1995) MDM2 transformation in the absence of p53 and abrogation of the pl07 Gl cell-cycle arrest. Oncogene 11: 2445-2449.

105. Sun P, Dong P, Dai K, Hannon GJ, Beach D. (1998) p53-independent role of MDM2 in TGF $\beta 1$ resistance. Science 282: 2270-2272.

106. Shvarts A, Steegenga WT, Riteco N, et al. (1996) MDMX: a novel p53-binding protein with some functional properties of MDM2. EMBO J. 15: 5349-5357.

107. Leveillard T, Gorry P, Niederreither K, Wasylyk B. (1998) MDM2 expression during mouse embryogenesis and the requirement of p53. Mech. Dev. 74: 189-193.

108. Fiddler TA, Smith L, Tapscott SJ, Thayer MJ. (1996) Amplification of MDM2 inhibits MyoDmediated myogenesis. Mol. Cell. Biol. 16: 50485057.

109. Brown DR, Thomas CA, Deb SP. (1998) The human oncoprotein MDM2 arrests the cell cycle: elimination of its cell-cycle-inhibitory function induces tumorigenesis. EMBO J. 17: 2513-2525.

110. Shvarts A, Bazuine M, Dekker P, et al. (1997) Isolation and identification of the human homolog of a new p53-binding protein, Mdmx. Genomics 43: 34-42. 